\title{
The preparation, friction and wear analysis of TiAl base self-lubricating composite materials joint bearing
}

\author{
Wu Yayu ${ }^{1, a}$, Yang Liying ${ }^{1, b^{*}}$, Luan Jiahang ${ }^{1, c}$, LI Wenwen $^{1, d}$ \\ ${ }^{1}$ School of Mechanical Engineering, University of Jinan, Jinan, 250022, China \\ a1436215041@qq.com, bme_YangLy@ujn.edu.cn, 522064051@qq.com, d1085168042@qq.com
}

Keywords: friction and wear analysis, TiAl base self-lubricating composite materials, joint bearing.

\begin{abstract}
For the study of the actual performance of TiAl base self-lubricating joints bearing, this paper adopts the vacuum hot-pressing sintering technology to prepare the self lubricating joint bearing blank body. Prepare TiAl base self-lubricating joints bearing through the mechanical processing method. And carry out high temperature friction and wear experiment. Provide experiment basis for the use of self lubricating joint bearing.
\end{abstract}

\section{Introduction}

Joint bearing is a kind of special structure of the sliding bearing,which is consist of mainly a spherical inner ring and a spherical outer ring ${ }^{[1]}$. Its structure as shown in figure 1.

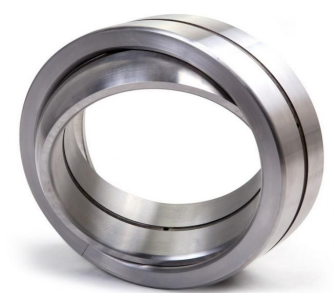

Figure1 joint bearing structure

Ordinary joint bearing must work under lubricating oil or grease.Under the environment of high temperature lubricating oil and grease are easy to dilute and evaporate,causing friction pair in a boundary friction even dry friction condition. This will aggravate bearing wear ${ }^{[2]}$. Self-lubricating composite material formed by adding solid lubricant in the TiAl alloy is an effective means to solve the joint bearing wear and tear under the condition of high temperature thermal coupling ${ }^{[3]}$. 


\section{Preparation of TiAl-based self-lubricating composite material}

The preparation process of TiAl-based self-lubricating composite material is as follows figure 2.

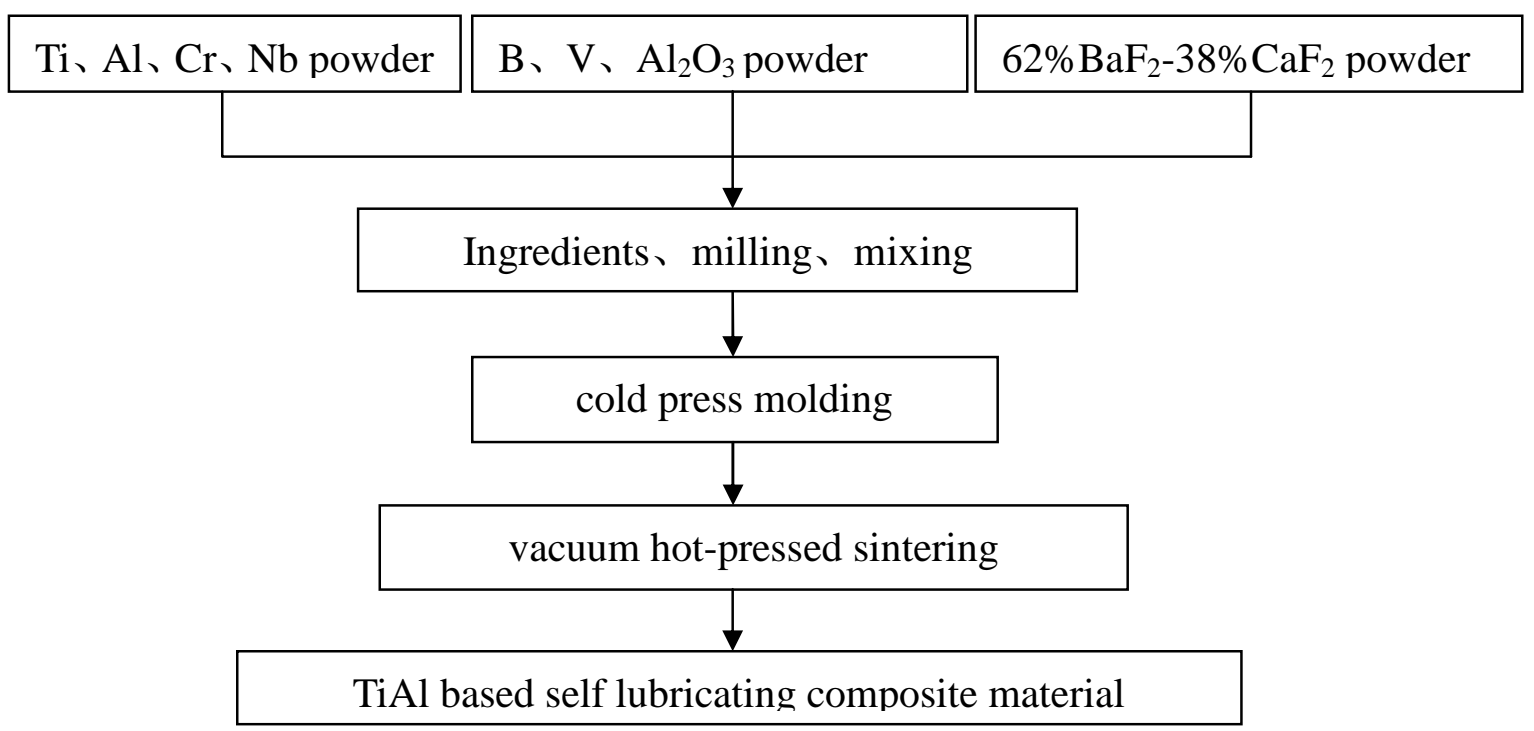

Figure 2 The preparation process of TiAl-based self-lubricating composite material Experimental material. experimental materials include $\mathrm{Ti}$ powder, $\mathrm{Al}$ powder, $\mathrm{Cr}$ powder, $\mathrm{Nb}$ powder, $\mathrm{V}$ powder, $\mathrm{B}$ powder, $\mathrm{Al}_{2} \mathrm{O}_{3}$ powder. Its physical parameters are shown in Table 1 .

Table1 experimental materials and physical parameters

\begin{tabular}{|c|c|c|c|c|c|c|c|c|c|}
\hline materials & $\mathrm{Ti}$ & $\mathrm{Al}$ & $\mathrm{Cr}$ & $\mathrm{Nb}$ & $\mathrm{V}$ & $\mathrm{B}$ & $\mathrm{Al}_{2} \mathrm{O}_{3}$ & $\mathrm{BaF}_{2}$ & $\mathrm{CaF}_{2}$ \\
\hline purity (wt\%) & 99.99 & 99.9 & 99.5 & 99.95 & 99.9 & 99.9 & 99.99 & 99.5 & 99.5 \\
\hline $\begin{array}{c}\text { density } \\
\left(\mathrm{g} / \mathrm{cm}^{3}\right)\end{array}$ & 4.51 & 2.69 & 7.22 & 8.57 & 6.1 & 2.3 & 3.97 & 4.89 & 3.18 \\
\hline $\begin{array}{c}\text { granularity } \\
(\mu \mathrm{m})\end{array}$ & 48 & 75 & 48 & 48 & 48 & 25 & 48 & 10 & 10 \\
\hline
\end{tabular}

Mixing. The Ti powder, $\mathrm{Al}$ powder, $\mathrm{Cr}$ powder, $\mathrm{Nb}$ powder, $\mathrm{V}$ powder, $\mathrm{B}$ powder, $\mathrm{Al}_{2} \mathrm{O}_{3}$ powder were mixed in accordance with the atomic ratio Ti44Al2 $\mathrm{Cr} 8 \mathrm{Nb} 3 \mathrm{~V} 0.5 \mathrm{~B} 0.5 \mathrm{Al}_{2} \mathrm{O}_{3}$. And add the solid lubricant $62 \% \mathrm{BaF}_{2}-38 \% \mathrm{CaF}_{2}$ eutectic which mass fraction respectively is $5 \%, 8 \%, 11 \%, 14 \%, 17 \%$, $20 \%$. use the KE -2L type planetary ball mill for milling the mixed powder.In the process of ball milling, milling tank were filled with inert gas argon to prevent oxidation of mixed powder. The milling medium was alumina ball, the mass ratio of ball powder was $10: 1$, the milling time is $4 \mathrm{~h}$, the speed of ball milling tank was $300 \mathrm{r} / \mathrm{min}^{[4]}$.

the figure 2 is the morphology of mixed powder under the microscope, it can been seen that from the figure the TiAl based mixed powder is mainly composed of irregular shape powder, and the particle distribution of mixed powder is wide,which have both ellipsoidal. Rod and large particles with irregular shape, small particles and irregular shape. Studies have shown that the hot pressing performance of powder which is formed of a variety of size particle. Because in the hot pressing process the small particles of this powder can easily move and filled into the pores in large particles, the hot pressed compacts density and intensity of a variety of particle size of powder are higher than the single particle size of powder. Therefore, the hot forming performance of this mixed powder is better. 


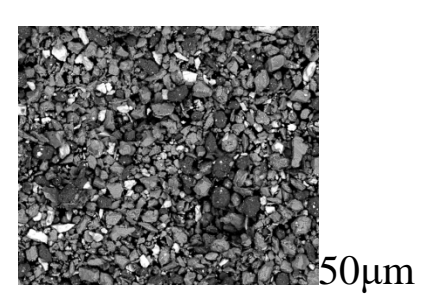

figure 3 The morphology of mixed powder

Analysis of powder oxidation and uniformity. In the milling process, Whether the powder is oxidized and the distribution uniformity of powder are the two key factors which can greatly influence the performance of TiAl-based self-lubricating composite material. For the analysis of whether the powder is oxidized, the control experiment is designed that other conditions are the same, just change the only parameters of ball milling time is $2 \mathrm{~h}$, analyze whether the powder is oxidized by using EDS scanning energy spectrum in the milling process. Figure 3 (a) and figure 3 (b) shows that The oxygen peak height of EDS spectrum is almost equal for milling $4 \mathrm{~h}$ and milling $2 \mathrm{~h}$, which indicate the mixed powder is not oxidized.

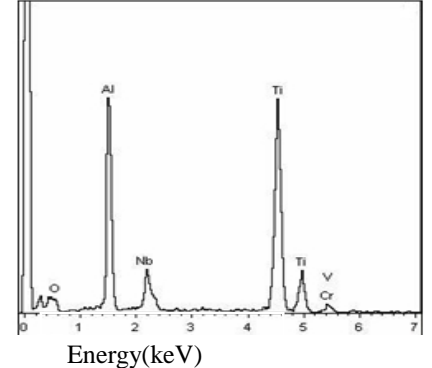

(a)

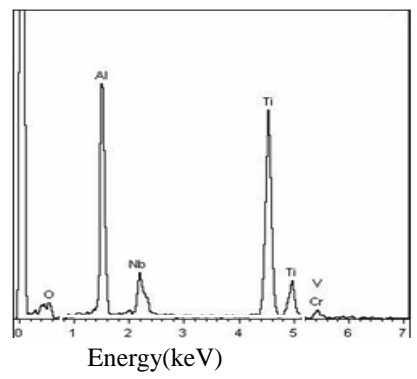

(b)

Figure 4 EDS scanning energy spectrum of mixed powder

For the analysis of the distribution uniformity of each element in the Mixed powder, use the EDS scanning. Figure 4 shows the distribution of mapping element of mixed powder, Ti powder, Al powder, $\mathrm{Cr}$ powder, $\mathrm{Nb}$ powder, $\mathrm{V}$ powder of the Mixed powder are evenly distributed better. the Mixed powder after milling is not oxidized and have good uniformity.
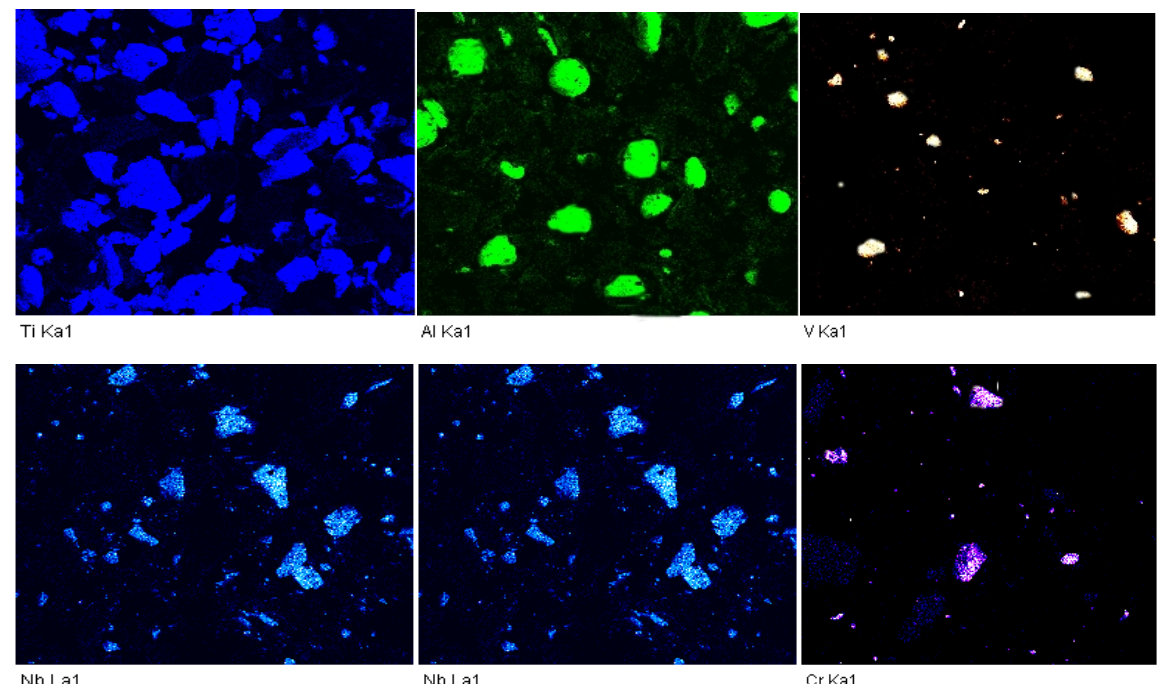

Figure 5 the distribution of mapping element of mixed powder

Cold forming and hot pressing. Place the milled powders in a mold, then Cold forming in the FW-4 hydraulic pressure testing machine. Apply pressure $40 \mathrm{KN}$, pack $15 \mathrm{~min}$. The cold forming sample was hot press forming in ZT-70-20Y type vacuum sintering furnace. Specific process: temperature is heated from room temperature to 1300 , respectively incubate $50 \mathrm{~min}$ at $600{ }^{\circ} \mathrm{C}$, 
$800{ }^{\circ} \mathrm{C}, 1000{ }^{\circ} \mathrm{C}$. At $1300{ }^{\circ} \mathrm{C}$, the pressure is applied to $30 \mathrm{MPa}$, incubating $120 \mathrm{~min}$. And then cool with the furnace.Figure 5 is TiAl-based self-lubricating composite material specimen ${ }^{[5]}$. The specimen is processed by Machine processing, obtaining the bearing inner and outer rings. And then assemble to get the joint bearing, As shown in figure 6 .

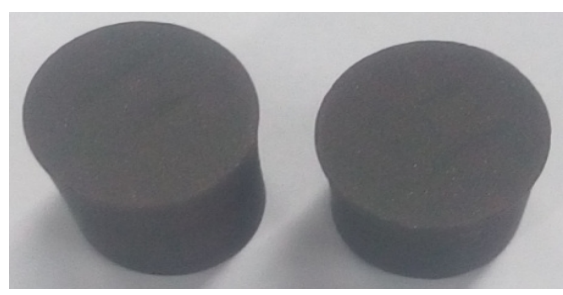

Figure 6 composite material specimen

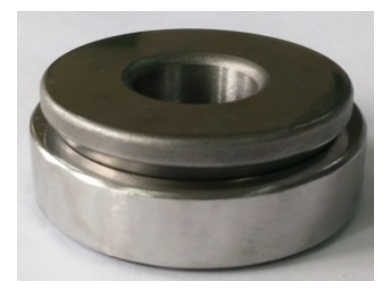

Figure 7 joint bearing assembly drawing

\section{the friction test of TiAl base self-lubricating joints bearing}

This article is tested in MMG - 10 type the friction and wear test machine. During the trial, joint bearing inner ring is directly installed on the machine spindle, Joint bearing outer ring is installed on the jig and connected by transition fit, fixturing with a set screw. During the trial, the load is imposed by loading shaft. Joint bearing inner ring do relative rotation with outer ring in the spindle driven. The friction temperature is measured by thermocouple directly.

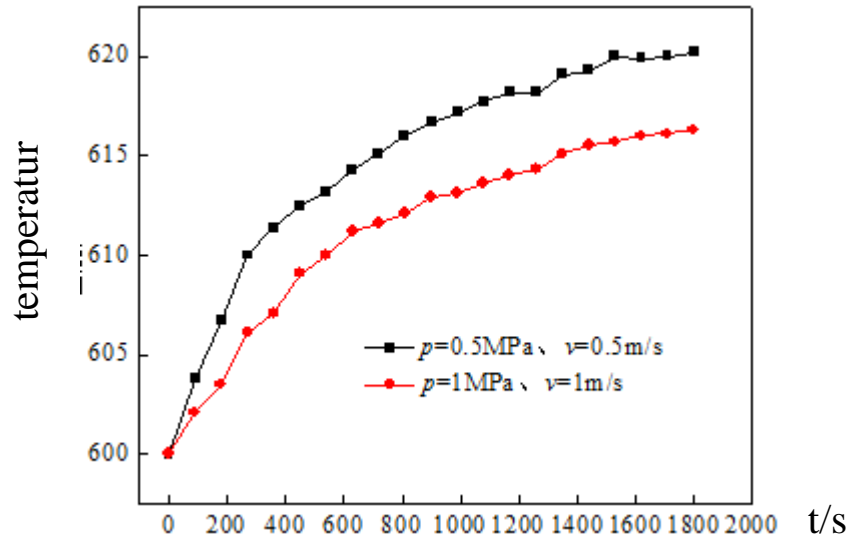

Figure 8 temperature change curve over time

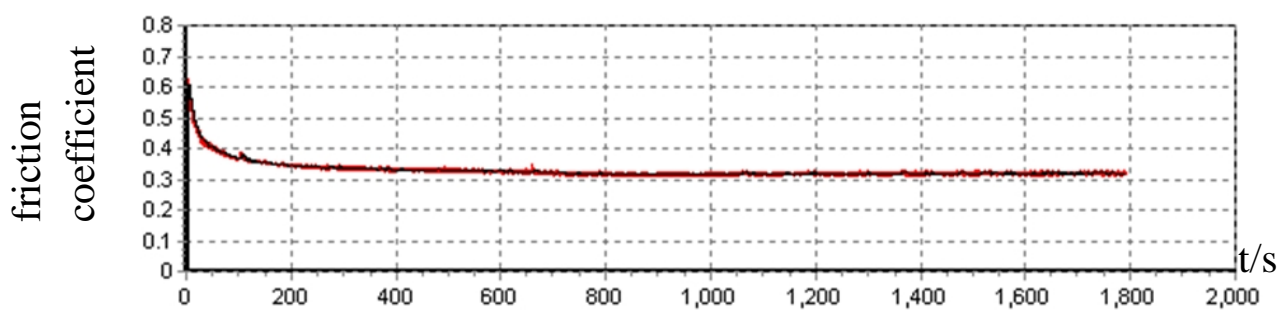

(a)

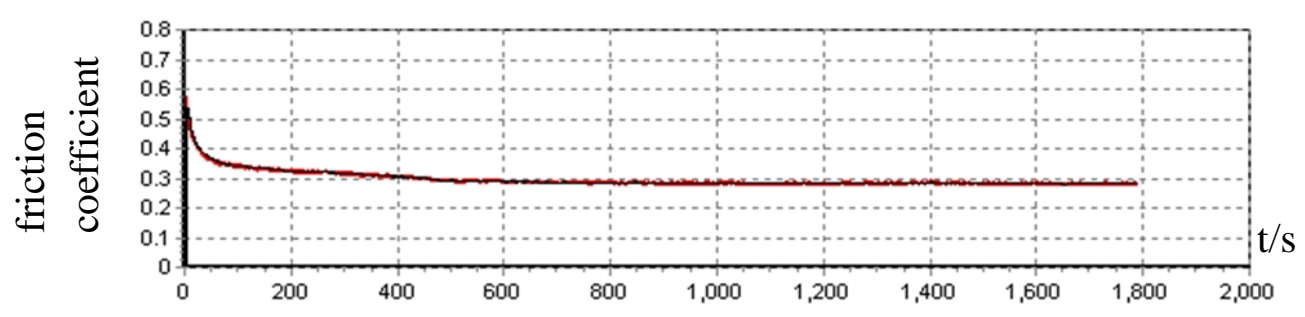

(b)

Figure 9 friction coefficient curve over time 
Test temperature is $600^{\circ} \mathrm{C}$, the contact pressure is $0.5 \mathrm{MPa}, 2 \mathrm{MPa}$ respectively. Sliding velocity is $0.5 \mathrm{~m} / \mathrm{s}, 1 \mathrm{~m} / \mathrm{s}$ respectively. The test time is $30 \mathrm{~min}^{[6]}$. The test results are shown in figure 7.Test temperature increases over time, but increased gently.

Figure $8(\mathrm{a})$ is the curves of friction coefficient with time as the contact pressure is $0.5 \mathrm{MPa}$, sliding speed is $0.5 \mathrm{~m} / \mathrm{s}$; Figure $8(\mathrm{~b})$ is the curves of friction coefficient with time as the contact pressure is $2 \mathrm{MPa}$, sliding speed is $1 \mathrm{~m} / \mathrm{s}$.

\section{Summary}

the friction coefficient of TiAl-based self-lubricating composite material are relatively stable under different conditions. And with the increase of contact pressure and Sliding velocity the friction coefficient Shows a trend of decrease, but the decline is smaller. when the contact pressure is $2 \mathrm{MPa}$, sliding speed is $1 \mathrm{~m} / \mathrm{s}$, the friction coefficient can reach 0.29 .

\section{Acknowledgements}

This work was financially supported by Key research and development project of Shandong Province(2016GGX102034).

\section{References}

[1] Chen Jigang, Yang Yulin, Xia Zhenwei etc. Integral type bearing outer ring joint forming technology present situation and development trend [J]. Journal of bearing, 2013, (9) : 58-62.

[2] Hu Qiwang, li Chunqing, Shen Jifang etc. Based on the ANSYS grader with centripetal knuckle bearing improvement [J]. Journal of bearing, 2010, (6) : 12-14.

[3] Xu Zeng. Tribological properties of titanium aluminium base self-lubricating composites research [D]. Wuhan: wuhan university of technology, 2013.

[4] Yang liying. The high temperature self-lubricating TiAl alloy preparation and its performance study [D]. Wuhan: wuhan university of technology, 2008.

[5] Liu Di, Zhang Lijun, lei. Preparation and application status of TiAl alloy [J]. Journal of titanium industry progress, 2014, (4) : 11-15.

[6]Guo Junde. Preparation of iron-based high-temperature self-lubricating materials and its tribological characteristics research [D]. Lanzhou: lanzhou university of technology, 2014. 